\title{
Synthesis of advanced ceramics by hydrothermal crystallization and modified related methods
}

\author{
José ORTIZ-LANDEROS ${ }^{\mathrm{a}}$, Carlos GÓMEZ-YÁÑEZa , Rigoberto LÓPEZ-JUÁREZ ${ }^{\mathrm{b}, *}$, \\ Iván DÁVALOS-VELASCO ${ }^{\mathrm{a}}$, Heriberto PFEIFFER ${ }^{\mathrm{c}}$ \\ ${ }^{a}$ Departamento de Ingeniería Metalúrgica, Escuela Superior de Ingeniería Química e Industrias Extractivas, IPN, \\ UPALM, Av. Instituto Politécnico Nacional s/n, CP 07738, México DF, México. \\ ${ }^{b}$ Centro de Ciencias Aplicadas y Desarrollo Tecnológico, Universidad Nacional Autónoma de México, A.P. 70-186, \\ Coyoacán, México D.F., México. \\ ${ }^{c}$ Instituto de Investigaciones en Materiales, Universidad Nacional Autónoma de México, Circuito exterior $s / n$, \\ Ciudad Universitaria, Del. Coyoacán, CP 04510, México DF, México.
}

Received August 29, 2012; Accepted October 9, 2012

(C) The Author(s) 2012. This article is published with open access at Springerlink.com

\begin{abstract}
The present article aims to give a brief overview about the advantages of the hydrothermal crystallization method for the synthesis of advanced ceramics. Emphasis is given, not only on the conventional hydrothermal crystallization, but also on some of its variants; such as ultrasound-assisted, electrochemical-assisted, microwave-assisted and surfactant-assisted hydrothermal methods which open up new opportunities for the synthesis of ceramic materials with novel properties demanded for advanced applications. In the current work the synthesis of barium titanate $\left(\mathrm{BaTiO}_{3}\right)$, lithium metasilicate $\left(\mathrm{Li}_{2} \mathrm{SiO}_{3}\right)$ and sodium-potassium niobate $(\mathrm{Na}, \mathrm{K}) \mathrm{NbO}_{3}$ powders are reported as cases of study.
\end{abstract}

Key words: hydrothermal synthesis; barium titanate; $\mathrm{Li}_{2} \mathrm{SiO}_{3}$; potassium-sodium niobate

\section{Introduction}

A general definition of hydrothermal process has been proposed by K. Byrappa and M. Yoshimura as follow: "the term hydrothermal refers to any heterogeneous chemical reaction in the presence of a solvent (whether aqueous or nonaqueous) above room temperature and at pressure greater than $1 \mathrm{~atm}$ in a closed system" [1]. In spite of this definition, which reaches a good

* Corresponding author.

E-mail: rigobertolj@yahoo.com.mx consensus describing any hydrothermal process, it is important to keep in mind that depending on the field of study it is possible to find several other related terms. An example of this is the term alcothermal that makes reference to the type of solvent used [2].

The initial work related to hydrothermal synthesis of materials is attributed to R. W. Bunsen, who grew barium and strontium carbonate at temperatures above $200{ }^{\circ} \mathrm{C}$ and pressures above 100 bars in 1839. After that in 1845, E. Schafhautl [3] observed the formation of small quartz crystals upon transformation of precipitated silicic acid in a steam digester, the forerunner of the autoclave. Actually, the earliest 
studies on hydrothermal reactions were carried out by geologists in order to understand the petrogenesis of metamorphic rocks and minerals under hydrothermal conditions [2-5], and it wasn't until the 1940's that more intensive work about hydrothermal synthesis began with the preparation of single crystals of quartz and zeolites [1]. An interesting historical review about the first systematic studies carried out involving hydrothermal reactions was reported by R. Roy and $\mathrm{O}$. F. Tutle [6].

Nowadays, the conventional hydrothermal method as well as its variants have emerged as a versatile synthesis option for the preparation of multifunctional ceramics materials including electronic ceramics, bioceramics, catalysts, catalyst supports, membranes and ceramics with optical properties, among others [1,2,7-18].

The main advantage of hydrothermal synthesis over the conventional ceramic process of solid state reaction is the lower temperatures of reaction. In fact, in addition to precursor phase preparation, pure and well crystallized materials can be synthesized directly by hydrothermal reactions, thus avoiding further thermal treatments (i.e., hydrothermal crystallization) [19-23]. This characteristic offers the possibility to obtain submicrometric and even nanometric or nanostructured materials $[2,24]$.

In addition, hydrothermal crystallization also shows some advantages over other non-conventional processes of soft chemistry, such as sol-gel and coprecipitation. For instance, in hydrothermal crystallization the reaction times are shorter with a good control of the crystallization, crystal size, purity and even morphology of the products [25].

\subsection{Conventional hydrothermal crystallization}

In a typical hydrothermal synthesis, precursors are commonly prepared as solutions or suspensions, which are subsequently treated under autogenously pressures reached by using an autoclave vessel. Hydrothermal crystallization can be split into two stages, i.e., dissolution-supersaturation and subsequent crystallization [26]. In the first stage, dissolution of the precursor is promoted by both temperature and pressure, giving place to the formation of species in solution which are more prone to react and obtain the desirable product. This is assumed to be a stable phase under the selected hydrothermal conditions once the critical nucleation occurs.
For instance, the synthesis of a metal oxide under hydrothermal conditions can be visualized as follows [3]. At the beginning of the process as the temperature is increased, the hydrolysis of a metal salt precursor produces metal hydroxides. Then, when the system has reached a more elevated temperature the hydroxides are dehydrated, yielding the metal oxide. This is favored by the decrease of the dielectric constant of water and the increase of the oxygen solubility in water due to the critical conditions.

During the crystallization stage, particle growth is also present and takes place by re-dissolution and re-precipitation of the already formed phases. The growth of larger crystals is observed from those of smaller size, which is assumed to have a higher solubility. This phenomenon is known as Oswald ripening [27] and it happens during the second stage of the whole process. However, it is important to mention that nucleation and growth of amorphous phases or intermediate phases that are kinetically favored may takes place with further crystallization of the desirable phase only after longer periods of time. Based on this, it is clear that in a conventional hydrothermal synthesis, the composition of the precursor solution, temperature (including heating rate and reaction temperature), vessel pressure, and reaction time are the principal variables of any hydrothermal process.

In order to improve the performance of the conventional process, several techniques have been coupled with the hydrothermal crystallization method. In general, the resulting hybridized synthesis methods, such as ultrasound-assisted hydrothermal, electrochemical-assisted hydrothermal, microwaveassisted hydrothermal and surfactant-assisted hydrothermal techniques, can offer additional advantages over the conventional hydrothermal method. These include the reduction of reactions times and energy savings. This may also modify the characteristics of the products, such as purity, particle size, particle size distribution and morphology.

\subsection{Ultrasound-assisted hydrothermal crystallization}

This technique could be performed such as an ultrasound pretreatment of precursor solution and its further hydrothermal crystallization or the simultaneous use of ultrasound under hydrothermal conditions [28]. In both cases, the main benefits are the increase of the reaction kinetic and obtaining small 
particle sizes. For example, Meskin et al. [29] successfully prepared the pure monoclinic phase of hafnium oxide $\left(\mathrm{HfO}_{2}\right)$ by ultrasound-assisted hydrothermal method at $250{ }^{\circ} \mathrm{C}$ for $0.5 \mathrm{~h}$. It was observed that by using conventional methods, the crystallization process takes more than $3 \mathrm{~h}$ and the obtained product contains small quantities of a secondary amorphous phase. In the same manner, Rujiwatra et al. [30], prepared nanoparticles of the lead titanate $\left(\mathrm{PbTiO}_{3}\right)$ perovskite. In this case, an ultrasound pretreatment of the precursor solution promoted the crystallization of the phase at low temperature $\left(130{ }^{\circ} \mathrm{C}\right)$ and short hydrothermal reaction time $(3.5 \mathrm{~h})$. As in the single sonochemical reaction cases, the acustic cavitation phenomena and its related cavitational heating is believed to be the cause of the reaction rate improvement [31,32]. Other advantages attributed to the process are the possible formation of especial morphologies such as nanotubes [33], as well as the feasibility to prepared doped materials such as in the case of Fe-doped mesoporous $\mathrm{TiO}_{2}$ [34].

\subsection{Electrochemical-assisted hydrothermal crystallization}

Electrochemical-assisted hydrothermal crystallization is a useful technique to fabricate crystalline ceramic thin films. The main advantages attributed to the technique are improved purity of the products, lower reaction temperature and higher film growth rates [4,35-43]. Moreover, film microstructures can be controlled by changing synthesis parameters such as the electrolyte temperature and composition, current loading time, and current density. Additionally, since the ceramic films, anodically grown, are affected by the dissolution-recrystallization process under hydrothermal conditions can show different microstructures specially from the point of view of the morphology and grain size of the films $[35,36]$. For instance, $\mathrm{Wu}$ and Yoshimura [36] observed the formation of multilayer microstructures in the case of $\mathrm{BaTiO}_{3}$ films fabricated by the hydrothermalelectrochemical technique. This fact was explained by the competing reaction between the rate of the growth of anodic Ti-oxide films and the rate of precipitation from supersaturated $\mathrm{BaTiO}_{3}$ particles.

Hill et al. [37] prepared several $\mathrm{MnO}_{2}$ compounds with different crystalline phase ( $\alpha, \beta$ and $\gamma$ phases), as well as a number of different morphologies for the same phase $\left(\gamma-\mathrm{MnO}_{2}\right)$, such as needle-like and rod-like fibers. Different crystalline phase and morphology were obtained by controlling the synthesis parameters such as $\mathrm{pH}$, temperature and applied current density.

The technique also offers the possibility to prepare more complex oxides, e.g., $\mathrm{LiNiO}_{2}$ [38], solid solutions such as those reported by Masahiro Yoshimura $\left(\mathrm{Ca}_{1-x} \mathrm{Sr}_{x} \mathrm{TiO}_{3}\right)$ [39], doped materials such as $\mathrm{Eu}^{3+}: \mathrm{YVO}_{4}$ [40], and composite materias exposing good distribution of their components, such as hydroxyapatite/Ti [41] and hydroxyapatite/ $/ \mathrm{TiO}_{2}$ [42] composites.

\subsection{Microwave-assisted hydrothermal crystallization}

The first studies about microwave-assisted hydrothermal crystallization were conducted by Komarneni et al. [44] who synthesized different ceramic particles including $\mathrm{TiO}_{2}, \mathrm{ZrO}_{2}, \mathrm{Fe}_{2} \mathrm{O}_{3}, \mathrm{KNbO}_{3}$ and $\mathrm{BaTiO}_{3}$, and subsequently, several electroceramic powders such as $\mathrm{SrTiO}_{3}, \mathrm{Sr}_{0.5} \mathrm{Ba}_{0.5} \mathrm{TiO}_{3}, \mathrm{PbTiO}_{3}$, $\mathrm{BaZrO}_{3}, \quad \mathrm{SrZrO}_{3}, \mathrm{~Pb}\left(\mathrm{Zr}_{0.52} \mathrm{Ti}_{0.48}\right) \mathrm{O}_{3}$, and pyrochlore phases with formula $\mathrm{Pb}\left(\mathrm{Mg}_{1 / 3} \mathrm{Nb}_{2 / 3}\right) \mathrm{O}_{3}$ and $\mathrm{Pb}\left(\mathrm{Zn}_{1 / 3} \mathrm{Nb}_{2 / 3}\right) \mathrm{O}_{3}$ [45]. In these studies, authors observed several advantages over the conventional technique such as a significant reduction of reaction times and, in some cases, the formation of different crystalline phases than those obtained by the conventional hydrothermal route. They suggested that the success of the technique is due to the feasibility of microwave heating to dissolve the precursors during the hydrothermal reaction.

Actually, the use of microwave-assisted reactions in chemical synthesis is mainly based on the efficient heating by microwave irradiation [46]. In fact, in the case of microwave-assisted hydrothermal processes, microwave heating enhances the preparation of ultrafine and monodispersed powders. This is due to the fact that volumetric heating eliminates the thermal gradients, which favors a homogeneous nucleation and growth processes during the hydrothermal reaction. In addition, the microwave-assisted hydrothermal process enhances the product's purity and its affordability.

Some of the materials obtained via this method include $\mathrm{BaTiO}_{3}$; wherein the use of microwave heating promotes the tetragonal phase of the powders $[47,48]$ as well as the preparation of polycrystalline and homogeneous $\mathrm{BaTiO}_{3}$ thin films grown on Ti-covered polymer substrates [49]. Microwave-assisted 
hydrothermal reactions have been used for the synthesis of zeolite materials with special morphologies [50]: cerium carbonate hydroxide $\left(\mathrm{Ce}(\mathrm{OH}) \mathrm{CO}_{3}\right)$ showing hexagonal-shaped microplates [51], well-dispersed nanometric $\mathrm{TiO}_{2}$ particles [52], nitrogen doped $\mathrm{TiO}_{2}$ nanoparticles [53], $\mathrm{Ni}$ - and Zn-ferrite powders [54], nanosized bismuth tungsten oxide $\mathrm{Bi}_{2} \mathrm{WO}_{6}$ [55], $\quad \mathrm{AgIn}_{5} \mathrm{~S}_{8}$ nanoparticles with photocatalytic properties [56], well crystalline barium strontium titanate $\left(\mathrm{Ba}_{0.8} \mathrm{Sr}_{0.2} \mathrm{TiO}_{3}\right)$ [57], $\mathrm{Yb}^{3+}$ and $\mathrm{Tm}^{3+}$ co-doped $\beta-\mathrm{NaYF}_{4}$ phase [58]. Other examples are the synthesis of binary mixed metal oxides having composition of $\mathrm{Ce}_{0.75} \mathrm{Zr}_{0.25} \mathrm{O}_{2}$ [59], rod-like $\mathrm{LiMnO}_{2}$ nanocrystals [60], high purity Hectorite clays materials [61] and mixed $\mathrm{Co}_{3} \mathrm{O}_{4} / \mathrm{CoO}$ nanorods [62].

Finally, another interesting feature of microwave heating is its selective heating characteristic. Since different materials show different abilities to absorb microwave energy and to convert it into heat (loss factor), this phenomenon could be useful to select a suitable reaction system. Therefore, a reaction medium with high microwave absorbing properties can be chosen looking forward to efficient and rapid heating. The use of ionic liquids as solvents for hydrothermal reactions is a good example of this. In the same sense, the loss factor phenomena is the reason why some ferrite materials can be synthesized at low temperatures only when microwave heating is used [63]. Cao et al. [64] prepared successfully $\mathrm{ZnFe}_{2} \mathrm{O}_{4}$ nanoparticles, iron hydroxyl phosphates $\left(\mathrm{NH}_{4} \mathrm{Fe}_{2}\left(\mathrm{PO}_{4}\right)_{2} \mathrm{OH} \cdot 2 \mathrm{H}_{2} \mathrm{O}\right)$ nanostructures [65] as well as $\alpha-\mathrm{FeOOH}$ hollow spheres and $\alpha-\mathrm{Fe}_{2} \mathrm{O}_{3}$ nanoparticles [66] via microwave- assisted hydrothermal ionic liquid synthesis. Other synthesized materials are $\mathrm{Fe}_{3} \mathrm{O}_{4}$ nanorods [67] and $\mathrm{SnO}_{2}$ microspheres [68].

\subsection{Surfactant-assisted hydrothermal crystallization.}

The use of surfactants coupled with different routes of chemical synthesis has been used to control the crystallization of single particles, as well as to promote the ordering of these into more complex microstructures [69-74]. The surfactant-assisted hydrothermal method is a clear example of a bottom-up method for the synthesis of nanostructured ceramics [3,25], wherein different products exposing unique morphologies could be obtained as a result of surfactant acting as soft templates or growth-directing agent [71,75-87]. For instance, Zhao et al. [75] prepared crystalline calcium carbonate particles $\left(\mathrm{CaCO}_{3}\right)$ through the surfactant-assisted hydrothermal method. The obtained materials show several morphologies by using different solvents as well as different surfactants. The various morphologies include flower-like, belt-like, network-like, coralloid, and hexagonal morphologies, all of which exhibit different textural properties. The formation of the ordered superstructures takes place by a preferential aggregation mechanism due to the surfactants interaction with the primary formed nanoparticles.

$\mathrm{Xu}$ et al. [76] successfully synthesized $\gamma$-Bismuth molybdate $\left(\mathrm{Bi}_{2} \mathrm{MoO}_{6}\right)$ powders. It was observed that when the conventional hydrothermal route was used, ultrafine particles with particle sizes in the range of 100 to $200 \mathrm{~nm}$ were obtained. On the other hand, when poly vinyl pyrrolidone (PVP) was used as surfactant, powders exposing nanoplate morphology were formed, resulting in unusual optical properties.

Meng et al. [77] prepared crystalline $\mathrm{BiVO}_{4}$ with polyhedral, rod-like, tubular, leaf- like and spherical architectures via surfactant -assisted hydrothermal method by using the triblock copolymer P123. When the different samples were tested for the photodegradation of methylene blue, a remarkable influence of the morphology on the catalytic performance was observed.

García-Benjume et al. [78] prepared $\mathrm{TiO}_{2}-\mathrm{Al}_{2} \mathrm{O}_{3}$ mixed oxides via hydrothermal synthesis using Tween-20 as a microstructure directing agent. The synthesized powders presented an unusual hierarchical macro-mesoporous microstructures. The authors propose a formation mechanism where supramolecular arrays of surfactant (both vesicles and micelles) act as soft templates promoting the porous superstructures.

Another examples of hydrothermal synthesis wherein the use of several surfactants plays a key role in the formation mechanism of complex microestrustures and novel properties are as follows: synthesis of $\mathrm{Bi}_{2} \mathrm{Te}_{3}$ [79], silica microspheres with MCM 41 porous microstructure[71], $\mathrm{BiVO}_{4}$ photocatalysts [80], alumina nanotubes [81], hydroxyapatite nanoparticles [82], $\alpha-\mathrm{Fe}_{2} \mathrm{O}_{3}$ nanoparticles [83], $\mathrm{CoFe}_{2} \mathrm{O}_{4}$ nanorods [84], $\mathrm{YVO}_{4}: \mathrm{Eu}^{3+}$ powders [85], $\mathrm{ZnO}$ nanowires and nanopowders $[86,87]$ and lamellar ultrafine magnesium hydroxide [88].

The present work aims to shows the advantages of the hydrothermal crystallization method for the synthesis of advanced ceramics. Three cases studies are discussed, i.e., the preparation of ultrafine barium 
titanate $\left(\mathrm{BaTiO}_{3}\right)$ powders via the conventional hydrothermal method, the synthesis of lithium metasilicate $\left(\mathrm{Li}_{2} \mathrm{SiO}_{3}\right)$ via surfactant-assisted hydrothermal crystallization, and finally the preparation of sodium-potassium niobate $(\mathrm{Na}, \mathrm{K}) \mathrm{NbO}_{3}$ powders via microwave-assisted hydrothermal crystallization.

\section{Experimental}

\subsection{Low temperature synthesis of $\mathrm{BaTiO}_{3}$ ultrafine powders via conventional- hydrothermal method}

In spite of the fact that ceramic materials have been obtained by the conventional hydrothermal $(\mathrm{CH})$ route since mid-19th century, it was not until 1955 that the first barium titanate synthesis was recorded, which was based on hydrothermal crystallization from a titanium ester in an aqueous solution of barium soluble salt $[4,89]$. Since then a variety of ferroelectric and other electroceramics have been synthesized under different hydrothermal environments [89]. For the preparation of barium titanate (BT), a great variety of precursors has been used such as titanium dimetoxydineodecanoate with $\mathrm{Ba}(\mathrm{OH})_{2}$ [90], titanium peroxohydroxide $\left(\mathrm{TiO}_{2}(\mathrm{OH})_{2}\right.$ with $\left.\mathrm{Ba}(\mathrm{OH})_{2} \cdot 8 \mathrm{H}_{2} \mathrm{O}[91]\right), \mathrm{TiO}_{2}$ anatase with $\mathrm{Ba}(\mathrm{OH})_{2} \cdot 8 \mathrm{H}_{2} \mathrm{O}$ [92-94], $\mathrm{TiCl}_{4}$ with $\mathrm{BaCl}_{2} \cdot 2 \mathrm{H}_{2} \mathrm{O}$ [95], titanium loaded polymer support with $\mathrm{Ba}(\mathrm{OH})_{2}$ [95] and mineralizers such as $\mathrm{KOH}$ [4,94], $\mathrm{NaOH}$ [96], $\mathrm{NH}_{4} \mathrm{OH}$ [95] while in some cases, $\mathrm{Ba}(\mathrm{OH})_{2}$ hydrated or anhydrous was used as basic $\mathrm{pH}$ regulation source [90-91,93].

\subsubsection{Synthesis and characterization of $\mathrm{BaTiO}_{3}$ powders}

Fine $\mathrm{BaTiO}_{3}$ powders were synthesized by using anhydrous barium hydroxide $\mathrm{Ba}(\mathrm{OH})_{2}$ and titanium oxide $\mathrm{TiO}_{2}$ as precursors. $\mathrm{Ba}(\mathrm{OH})_{2}$ was used not only as a source of $\mathrm{Ba}$ but also to adjust $\mathrm{pH}$ and then to promote solubility [90-91,93]. Precursors were charged into a teflon-lined autoclave. The $\mathrm{Ba} / \mathrm{Ti}$ molar ratio in the mixed solution was fixed at 1 using a concentration ratio of $\mathrm{mBa}(\mathrm{OH})_{2}=\mathrm{mTiO}_{2}=0.5$. The $\mathrm{pH}$ obtained in the aqueous solution precursor was 12 . Subsequently, the reactor was heated to temperatures between $90{ }^{\circ} \mathrm{C}$ and $180^{\circ} \mathrm{C}$ for different reaction times of 48 and $72 \mathrm{~h}$. The obtained powders were washed with distilled water to remove soluble components and then dried at $100{ }^{\circ} \mathrm{C}$ for $24 \mathrm{~h}$.
Later, in a second step, the obtained powders were sintered via the spark plasma sintering (SPS) process. Powder was poured into a graphite die and sintered following a heating rate of $200{ }^{\circ} \mathrm{C} / \mathrm{min}$ under uniaxial pressure of $40 \mathrm{MPa}$. High pulse sequence current of $3000 \mathrm{~A}$ and $3.5 \mathrm{~V}$ were utilized. The sintering temperature was $1100{ }^{\circ} \mathrm{C}$ at a holding time of $3 \mathrm{~min}$. The crystalline structure and phase of the as-prepared and heat-treated powders were identified by X-ray powder diffractometry (XRD, $\left.\mathrm{Cu}-\mathrm{K}_{\alpha}\right)$. Size and morphologies of powders were examined by high resolution scanning-transmission electron microscopy HRSTEM techniques.

\subsubsection{Results and discussion}

$\mathrm{X}$-ray diffraction analysis indicates that crystalline BT phase can be obtained successfully at temperatures from $90{ }^{\circ} \mathrm{C}$ to $180{ }^{\circ} \mathrm{C}$ and times from $48 \mathrm{~h}$ to $72 \mathrm{~h}$. Figure 1 shows XRD patterns and estimated crystallite sizes, of the series of samples synthesized by hydrothermal reaction at $72 \mathrm{~h}$; only a small quantity of $\mathrm{BaCO}_{3}$ was detected as secondary phase (Fig. 1a). Figure $1 \mathrm{~b}$ shows crystallite sizes of different samples which were estimated based on the broadening of XRD pattern profiles by using the Scherrer's equation. In general, crystallite size augments with increasing the reaction temperature from $90{ }^{\circ} \mathrm{C}$ to $180{ }^{\circ} \mathrm{C}$. As expected, higher temperature and longer times results in bigger growth of crystallite.

The HRSTEM technique (Fig. 2) has shown in detail the particle size and morphology of powders obtained at different hydrothermal reaction times. In fact HRSTEM has shown that BT powders are constituted particles in the nanometric scale. It is revealed that reaction time has an effect on both particle size and morphology. Samples obtained at $48 \mathrm{~h}$ show a polygonal morphology with a main particle size of $75 \mathrm{~nm}$. On the other hand, samples obtained at $72 \mathrm{~h}$ are spherical with a particle size of about $130 \mathrm{~nm}$. HRSTEM analysis revealed that BT particles are made of crystallites smaller than $50 \mathrm{~nm}$, or in other words single particles are constituted of small coherent crystalline domains (Fig. 2b inset) the aforesaid can explain the crystallite size values estimated by XRD technique. For all the cases, samples prepared via $\mathrm{CH}$ synthesis have a significantly smaller particle size with respect to samples prepared via solid state reaction, which commonly shows a particle size in the range of microns. 


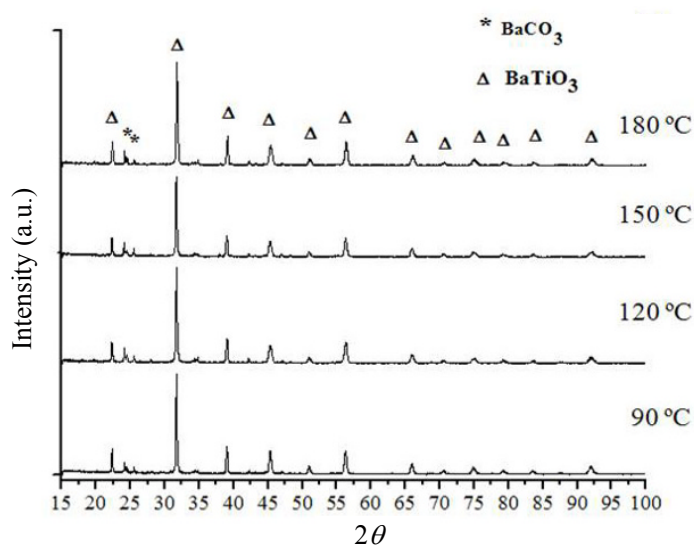

(a)

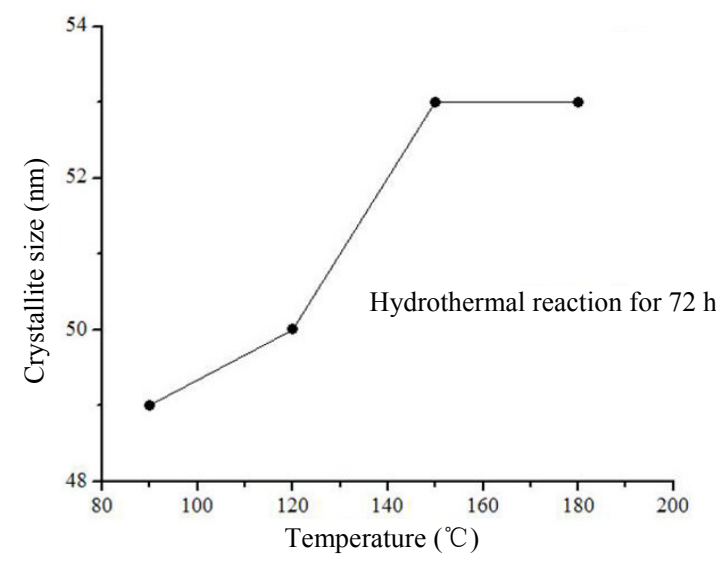

(b)

Fig. 1 (a) XRD patterns of BT produced by $\mathrm{CH}$ at $72 \mathrm{~h}$ and different temperatures, and (b) crystallite size comparison of $\mathrm{BT}$ produced via $\mathrm{CH}$ as a function of the reaction temperature.


Fig. 2 HRSTEM micrograph of BT particles produced by $\mathrm{CH}$ method: (a) $48 \mathrm{~h}$ and (b) $72 \mathrm{~h}$ of reaction at $180{ }^{\circ} \mathrm{C}$.

Finally, dense ceramic bodies were successfully produced by using the synthesized powders. With the use of Spark Plasma Sintering technique, densities of $95.88 \%$ of theoretical values were obtained for the ceramic bodies fabricated. These characteristics are desirables from the point of view that high density reduces the effect of pores on weakening dielectric constant. In addition, the transforming fraction increases with the decrease of grain size.

Summarizing, BT is able to be synthesized at low temperature using the hydrothermal method. The obtained powders are nanocrystalline and present a fine particle size. These characteristics offer the advantage of obtaining homogeneous and fine grain size microstructures throughout the sintering process.

\subsection{Synthesis of $\mathrm{Li}_{2} \mathrm{SiO}_{3}$ hollow microspheres via surfactant-assisted hydrothermal crystallization}

Lithium metasilicate has been the topic of several studies because of their potential application as tritium breeder material into the fusion reactors $[97,98]$ as an ionic conductor $[99,100]$ and as a candidate for luminescent materials [101,102]. In general, $\mathrm{Li}_{2} \mathrm{SiO}_{3}$ has been synthesized by the conventional solid-state reaction method, and only some chemical routes have been studied such as the sol-gel, microemulsion and combustion methods [103-105]. Similar to the case of other alkaline ceramics, it is complicated to prepare lithium ceramics with small particle sizes because of its tendency to sinter or to lose lithium through a sublimation process at high temperatures. In this sense, chemical synthesis routes provide the possibility to obtain unique microstructural and morphological characteristics and, therefore, new applications for these kind of materials. Here the preparation of $\mathrm{Li}_{2} \mathrm{SiO}_{3}$ by both surfactant-assisted hydrothermal approach $(\mathrm{SAH})$ and solid-state reaction $(\mathrm{SSR})$ is reported, establishing the effect of the synthesis route on the microstructural and textural characteristics of the resultant powders. 


\subsubsection{Synthesis and characterization of $\mathrm{Li}_{2} \mathrm{SiO}_{3}$ powders}

For the synthesis of SAH sample, lithium hydroxide $\left(\mathrm{LiOH} \cdot \mathrm{H}_{2} \mathrm{O}\right)$ and tetraethyl orthosilicate (TEOS, $\left.\mathrm{Si}-\left(\mathrm{OC}_{2} \mathrm{H}_{5}\right)_{4}\right)$ were used as starting materials. The used surfactant was Octylphenol ethylene oxide condensate (TRITON X-114). In the first step, certain quantity of the select non-ionic surfactant and $\mathrm{LiOH}$ reagents were dissolved in an ethylic alcohol aqueous solution. Later, stoichiometric amount of TEOS was added drop wise to the solution under mechanical stirring, followed by continuous stirring in an ultrasonic bath for $15 \mathrm{~min}$. The obtained homogeneous gel was transferred into a Teflon-lined stainless steel autoclave vessel. The hydrothermal reaction was performed under autogenously produced pressure at a temperature of $100{ }^{\circ} \mathrm{C}$ for $20 \mathrm{~h}$.

For the preparation of SSR samples the starting materials silicic acid $\left(\mathrm{H}_{2} \mathrm{SiO}_{3}\right)$ and lithium carbonate $\left(\mathrm{Li}_{2} \mathrm{CO}_{3}\right)$ were mixed in a mortar and calcined at $1000{ }^{\circ} \mathrm{C}$ for $7.5 \mathrm{~h}$. After which time the powders were ground milled again before repeating the thermal treatment. Samples were characterized by XRD, SEM, TEM, and $\mathrm{N}_{2}$ adsorption techniques.

\subsubsection{Results and discussion}

In order to reduce the number of experiments for obtaining the desirable pure phase of $\mathrm{Li}_{2} \mathrm{SiO}_{3}$, Eh-pH diagrams were constructed. Eh-pH diagrams show the stability region for the different stable ionic and nonionic species in aqueous solutions. The information is displayed as a plot of $\mathrm{pH}$ versus electrochemical potential, and it can be used as a simple resort to estimate phase equilibrium during the hydrothermal processes [23,106-107].

In this same sense, another well documented and powerful resource to determine the optimum conditions in systematic synthesis studies related to hydrothermal processes are both phase stability and yield diagrams. However, their construction involves more complex thermodynamic calculations. Their construction and the thermodynamic fundamentals have been also well documented [108-110].

In the current work, the specific hydrothermal reaction conditions were chosen based on Eh-pH equilibrium diagram for the $\mathrm{Li}-\mathrm{Si}-\mathrm{H}_{2} \mathrm{O}$ system only as a reference (Fig. 3). The Eh-pH diagram was drawn with the help of the FACT-Sage (Thermochemical Software and Databases) software [111], considering a total concentration of 0.8 molal and temperature of

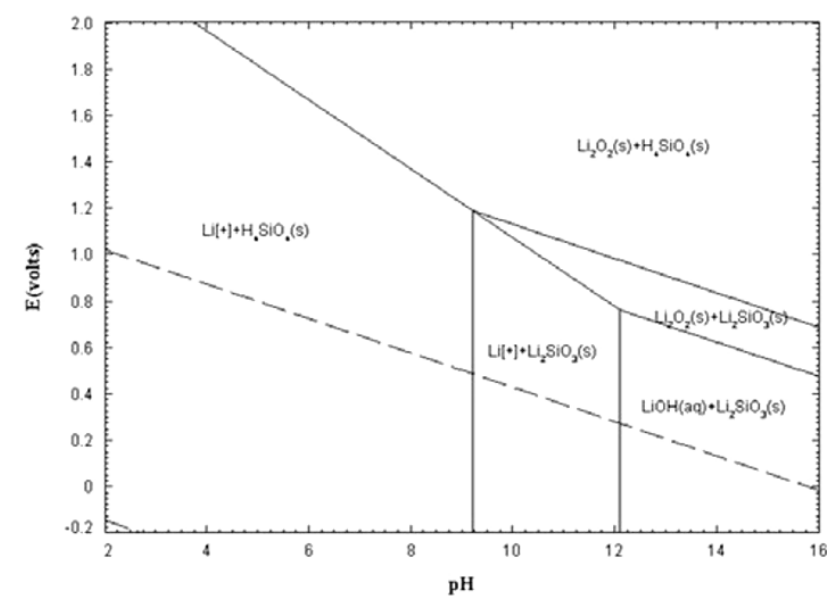

Fig. 3 Eh-pH diagram of the $\mathrm{Li}-\mathrm{Si}-\mathrm{H}_{2} \mathrm{O}$ system showing predominance domains of species. Diagrams were obtained considering a metal's ratio of $0.2<\mathrm{Si} /(\mathrm{Li}+\mathrm{Si})<0.333$, and temperature of $100{ }^{\circ} \mathrm{C}$.

$100{ }^{\circ} \mathrm{C}$.

The Eh-pH diagram reveals that the $\mathrm{Li}_{2} \mathrm{SiO}_{3}$ phase is stable at $\mathrm{pH}$ values up to $\sim 9.2$.

Figure 4 shows the XRD patterns of the different samples. The results show that both SSR and SAH samples correspond to $\mathrm{Li}_{2} \mathrm{SiO}_{3}$ phase (JCPDS card No. 29-0828). However, the SSR sample has a small impurity of lithium orthosilicate phase $\left(\mathrm{Li}_{4} \mathrm{SiO}_{4}\right)$. In addition, the XRD pattern profiles show some differences mainly on the line broadening. This is attributed to certain differences on crystallite size as a result of the synthesis method, surfactant addition and synthesis temperature. In fact, based on the analysis of XRD patterns profiles, crystallite size were estimated



Fig. 4 XRD patterns of as prepared lithium silicate powders; the different samples are: (a) SSR, and (b) SAH. 
as $14 \mathrm{~nm}$ and $>50 \mathrm{~nm}$ for SAH and SSR samples, respectively.

SEM photomicrographs show a noticeable change in morphology due to different synthesis methods (Fig. 5). SSR powders present morphology of dense aggregates with particle size varying from 3 to as higher as $25 \mu \mathrm{m}$ (Fig. 5a). On the other hand, SAH powders show well-defined spherical aggregates with particle size smaller than $3.5 \mu \mathrm{m}$ (Fig. 5b). Another important feature is the fact that these powders present a hollow microstructure. Similar to other reported systems [27], the possible formation mechanism of the hollow $\mathrm{Li}_{2} \mathrm{SiO}_{3}$ microspheres is attributed that takes place via Oswald ripening mediated process.
Figure 6 shows the TEM image corresponding to the SAH synthesized sample. The contrast observed in the bright-field image shows the hollow microstructure (Fig. 6a). Spherical aggregates present diameters between $2 \mu \mathrm{m}$ and $3 \mu \mathrm{m}$. The TEM electron diffraction pattern shows diffused rings, indicating that synthesized powders are polycrystalline (Fig. 6b). The SAED rings were indexed as the orthorhombic structure of $\mathrm{Li}_{2} \mathrm{SiO}_{3}$ according with the XRD JCPDS card No. 29-0828. In addition, TEM images revealed the formation of smaller and also hollow spheres about $400 \mathrm{~nm}$. In general, these observations suggest the presence of different mechanism of formation of the aggregates. Among them, the formation of the smallest
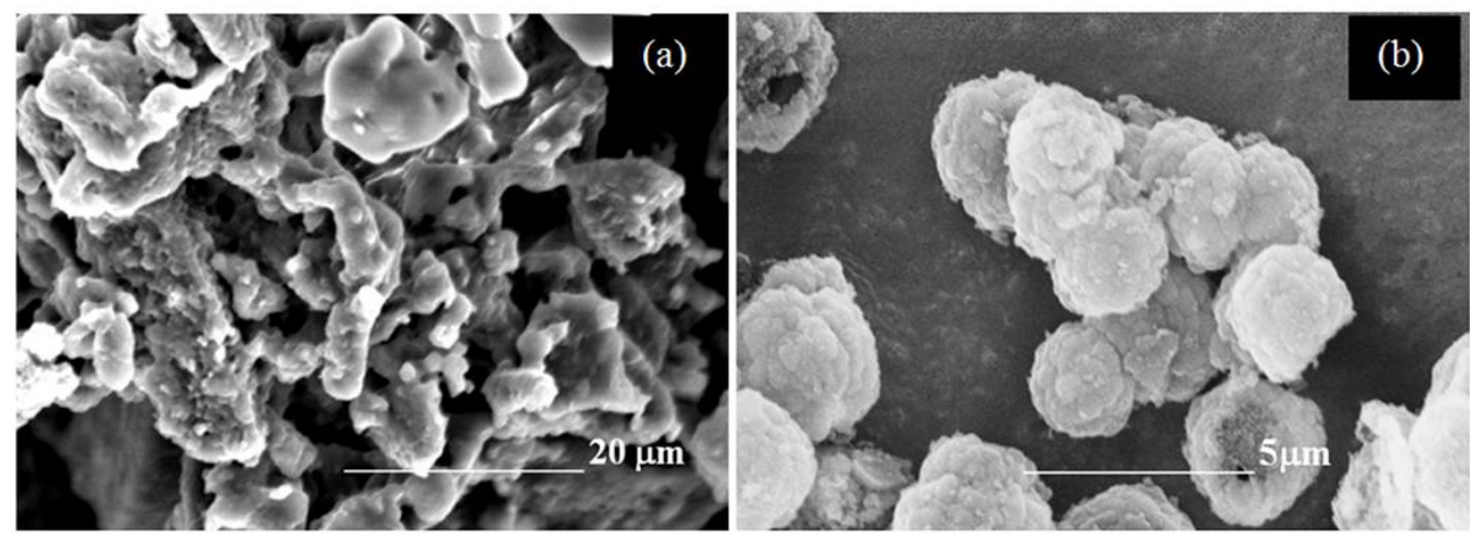

Fig. 5 (a) SEM images of samples prepared by solid state reaction and (b) surfactant-assisted hydrothermal methods.



Fig. 6 (a) Bright field TEM image of sample $\mathrm{SAH}$ and (b) indexed SAEDP of $\mathrm{Li}_{2} \mathrm{SiO}_{3}$. 
spherical aggregates is the result of the surfactant effect which plays the role of template. More details about the hydrothermal synthesis of $\mathrm{Li}_{2} \mathrm{SiO}_{3}$ in presence of different surfactants were previously reported [112].

Figure 7 shows adsorption-desorption isotherms corresponding to the different samples. According to the IUPAC classification [113-114], while the SSR sample shows a type III isotherm, the SAH sample presents a type II isotherm which can be attributed to a monolayer-multilayer adsorption on an open external surface of macroporous adsorbents. This sample shows a hysteresis loop type $\mathrm{H} 3$, which doesn't exhibit a limiting adsorption at high $\mathrm{P} / \mathrm{Po}$ values. This fact is usually interpreted as a result of the presence of slit-like pores. In the current work this fact was attributed to the presence of interparticle voids. In addition, it is noticeable that in the case of the SAH sample, volume adsorbed increases considerably compared to the SSR sample (Fig. 7, see scale), which corroborates the formation of smaller and more porous particles. Additionally, specific surface values were calculated by BET model [115]. Samples exposed surfaces area values of $69.5 \mathrm{~m}^{2} \mathrm{~g}^{-1}$ and $0.47 \mathrm{~m}^{2} \mathrm{~g}^{-1}$ for SAH and SSR, respectively.

The microstructure and textural properties obtained through the surfactant-assisted hydrothermal synthesis route, suggests advantages with respect to the solid state reaction method. These pure and nano-crystalline $\mathrm{Li}_{2} \mathrm{SiO}_{3}$ may be suitable to be used for certain applications such as $\mathrm{CO}_{2}$ absorption [103-105].

\subsection{One step synthesis of $\mathrm{K}_{0.5} \mathrm{Na}_{0.5} \mathrm{NbO}_{3}$ solid solutions via hydrothermal microwave-assisted method}

Today, synthesis of lead-free piezoceramics is of strong interest when looking at a more environmentally friendly option for the fabrication of optical and acoustic devices such as optical wave-guiding and frequency doubling [116-120]. The different studies have been focused on the preparation of sodium-bismuth titanates and potasium-sodiumniobates (KNN) [117,121-124]. These studies included both pure and doped compounds. In fact, among them, $\mathrm{KNN}$ are the most promising because of their good piezoelectric properties as well as their high Curie's temperature values [125]. With respect to the synthesis, a common problem faced by using the conventional solid state reaction route is that potassium and sodium are lost by sublimation during the calcinations and sintering stages at elevated temperatures. This affects the stoichiometry of the final products promoting the presence of secondary phases [126]. Other synthesis methods have been studied as an alternative proposal, such as sol-gel [127,128], Pechini [129] and conventional hydrothermal [130,131]. Among them, the sol-gel and Pechini approaches present the disadvantages of involving expensive precursors which in some cases may also be difficult to handle, as in the case of alkoxides.

The conventional hydrothermal method has been used to prepare sodium niobate, potassium niobate and potassium tantalite [132-134]. However, this method
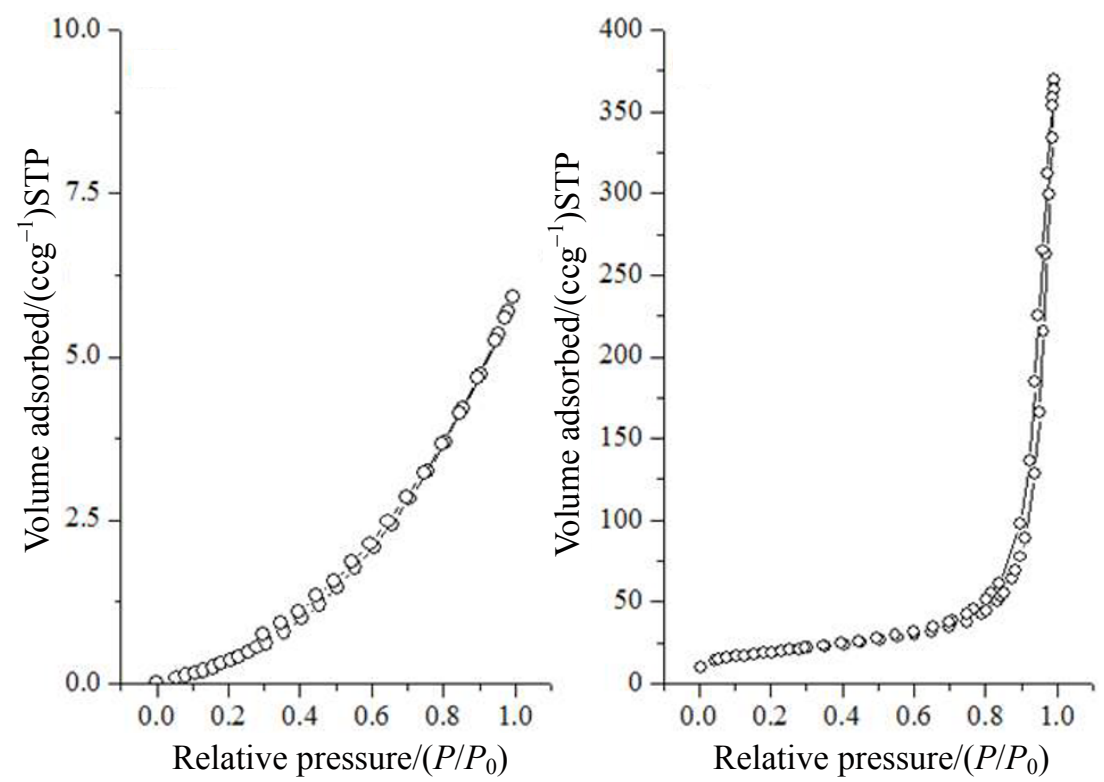

Fig. $7 \quad N_{2}$ physisorption isotherms of the prepared samples: (a) SSR, and (b) SAH. 
also presents certain difficulties to obtain pure phases and compositional homogeneous products in one step, making it necessary to perform further thermal treatments [135].

In the present work, the synthesis of KNN by conventional hydrothermal $(\mathrm{CH})$ and microwaveassisted hydrothermal (MAH) methods is reported.

\subsubsection{Synthesis and characterization of $\mathrm{K}_{\mathbf{0} .5} \mathrm{Na}_{0.5} \mathrm{NbO}_{3}$ solid solutions}

Potassium hydroxide ( $\mathrm{KOH} \geqslant 90 \%)$, Sodium hydroxide $(\mathrm{NaOH} 99 \%)$ and niobium pentoxide $\left(\mathrm{Nb}_{2} \mathrm{O}_{5} 99.99 \%\right)$ were used as starting materials. In the first step, an aqueous solution of $(\mathrm{KOH}+\mathrm{NaOH})$ was prepared. Based on previous studies [130,131], the molar ratio of 7.5:2.5 (KOH:NaOH) was chosen. After that, 2 grams of $\mathrm{Nb}_{2} \mathrm{O}_{5}$ were added to the alkaline solution. The formed suspension was stirred for 2 hours before the hydrothermal reaction.

For the synthesis of $\mathrm{CH}$ sample, the mixed precursor suspension was put in a Teflon-lined stainless steel autoclave, which was heated at $240{ }^{\circ} \mathrm{C}$ for $24 \mathrm{~h}$ by using an electric furnace and following a heating rate of $10{ }^{\circ} \mathrm{C} / \mathrm{min}$. After that, the autoclave reactor was cooled to ambient temperature and the obtained powders were filtered, washed several times with deionized water and finally dried at $120{ }^{\circ} \mathrm{C}$ for $2 \mathrm{~h}$.

Regarding the synthesis of MAH sample, a Teflon reinforced autoclave was used. The autoclave reactor was heated at $210{ }^{\circ} \mathrm{C}$ in a microwave oven CEM model MARS for $30 \mathrm{~min}$, followed by a heating rate of $14{ }^{\circ} \mathrm{C} / \mathrm{min}$. The power source in the oven was fixed at $800 \mathrm{~W}$. After hydrothermal reaction, the washing and drying steps were carried out.

Structural and microstructural characterization of the powders was performed by XRD and SEM techniques.

\subsubsection{Results and discussion}

$\mathrm{X}$-ray patterns corresponding to different synthesized samples are shown in Fig. 8.

It is noticed that when the conventional method was used two phases were obtained. The first one was identified as $\mathrm{KNbO}_{3}$ (JCPDS 71-2171), and the second one as $\mathrm{NaNbO}_{3}$ (JCPDS 01-074-2025). However, it is remarkable that for both phases, the obtained XRD patterns present certain shifts of their reflexions; this fact was clearly evident in the higher 2-thetha values peaks (see Fig. 8). This suggests that in both cases a partial degree of substitution $\left(\mathrm{Na}^{+1} \leftrightarrow \mathrm{K}^{+1}\right)$ was promoted, so it can be expressed as the obtaining of the $\mathrm{K}_{x} \mathrm{Na}_{1-x} \mathrm{NbO}_{3}(x>0.5)$ and $\mathrm{Na}_{1-y} \mathrm{NbO}_{3}(y<0.5)$ which are potassium and sodium enriched phases, respectively. On the other hand, the diffraction pattern of MAH sample shows only the peaks corresponding to the orthorhombic pure $\mathrm{KNbO}_{3}$ perovskite phase (JCPDS 71-2171). Of course, in this case the reflexions also shift to higher two theta values due to the incorporation of $\mathrm{Na}$ into the crystalline structure of $\mathrm{KNbO}_{3}$, and then the one-step formation of the $\mathrm{K}_{0.5} \mathrm{Na}_{0.5} \mathrm{NbO}_{3}$ solid solution phase (Fig. 8b). Actually, in a recent study Maeda et al. [135] prepared (K, $\mathrm{Na}) \mathrm{NbO}_{3}$ lead-free piezoelectric ceramics by using previously $\mathrm{CH}$ synthesized powders. However, in this case thermal treatment was required for the solid solution formation. Therefore, this work is reported for the first time the use of microwave-hydrothermal processing for the preparation of this kind of materials in one step.

After that, $\mathrm{CH}$ powders were thermally treated at temperatures of $600{ }^{\circ} \mathrm{C}$ and $800{ }^{\circ} \mathrm{C}$ in order to obtain the $\mathrm{K}_{0.5} \mathrm{Na}_{0.5} \mathrm{NbO}_{3}$ phase. Figure 9 shows the XRD patterns of the different samples.

Figure 9 shows the evolution of the KNN phase by both sodium and potassium diffusion among the solid particles throughout the further thermal treatments. In fact, the reaction can be described as follow:

$$
\begin{gathered}
n \mathrm{~K}_{x} \mathrm{Na}_{1-x} \mathrm{NbO}_{3}+(1-n) \mathrm{K}_{y} \mathrm{Na}_{1-y} \mathrm{NbO}_{3} \longrightarrow \\
\mathrm{K}_{0.5} \mathrm{Na}_{0.5} \mathrm{NbO}_{3}
\end{gathered}
$$

where $\mathrm{K}_{x} \mathrm{Na}_{1-x} \mathrm{NbO}_{3} \quad(x>0.5)$ and $\mathrm{Na}_{1-y} \mathrm{NbO}_{3} \quad(y<0.5)$ are the potassium and sodium enriched phases, respectively.

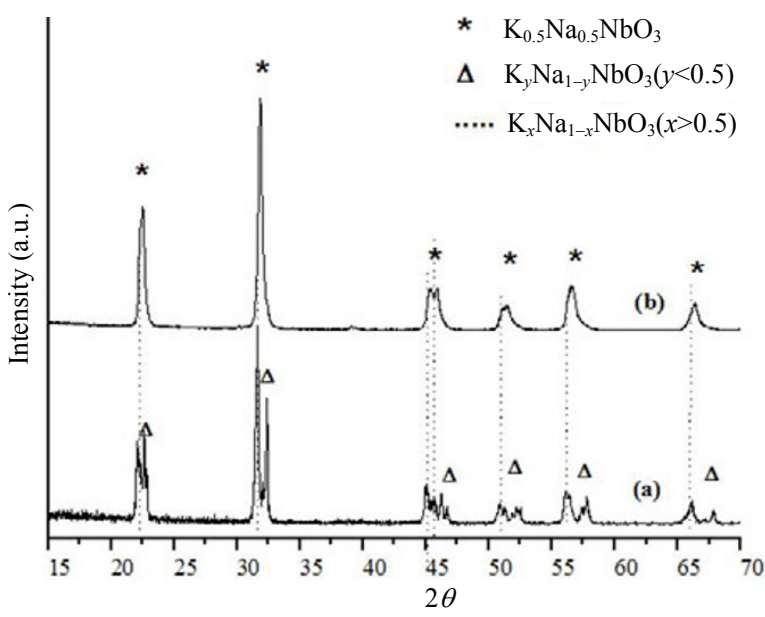

Fig. 8 KNN powders synthesized by: (a) conventional hydrothermal at $240{ }^{\circ} \mathrm{C}$ for $24 \mathrm{~h}$, and (b) microwave-assisted hydrothermal at $210{ }^{\circ} \mathrm{C}$ for $30 \mathrm{~min}$. 


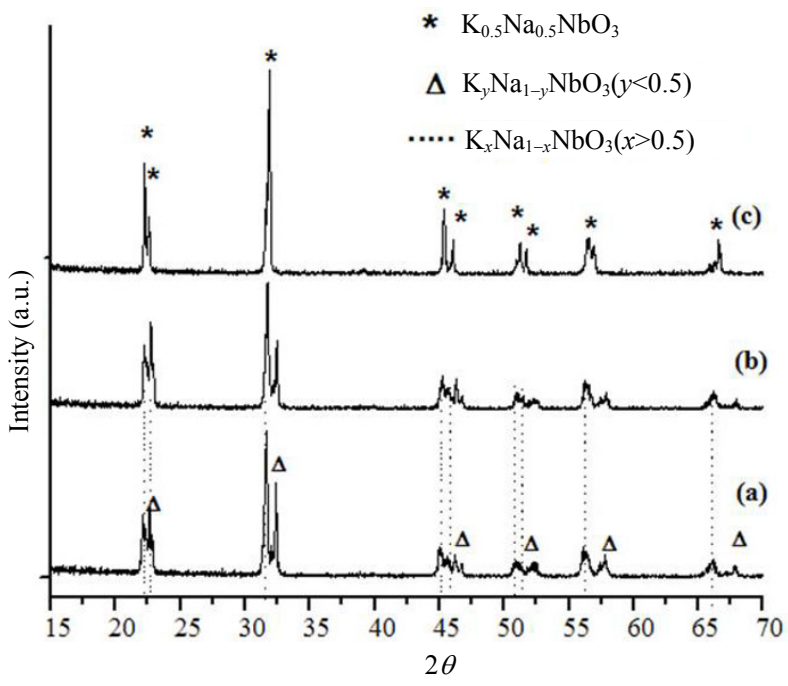

Fig. 9 XRD patters of $\mathrm{CH}$ samples: (a) as prepared powders, (b) calcined at $600{ }^{\circ} \mathrm{C}$ and (c) calcined at $800{ }^{\circ} \mathrm{C}$.

The complete formation of $\mathrm{K}_{0.5} \mathrm{Na}_{0.5} \mathrm{NbO}_{3}$ from the $\mathrm{CH}$ powders was finally reached after calcinations at $800{ }^{\circ} \mathrm{C}$.

Finally, Figure 10 show the SEM images of KNN samples prepared by calcinations of $\mathrm{CH}$ powders at $800{ }^{\circ} \mathrm{C}$ and MAH sample.

Both samples are constituted by ultrafine powders with aggregates in the micrometric range. However, it is clear that smaller particles were obtained in $\mathrm{MAH}$ sample. In fact, this sample is constituted by submicrometric primary particles smaller than $500 \mathrm{~nm}$ (Fig. 10b). These results can be attributed to both the shorter time of hydrothermal reaction as well as the direct crystallization of KNN phase without thermal treatment.

Then summarizing, KNN powders with chemical composition of $\mathrm{K}_{0.5} \mathrm{Na}_{0.5} \mathrm{NbO}_{3}$ are able to be successfully synthesized by the hydrothermal technique. The conventional method gives the possibility of obtaining ultrafine powders, and in fact, reduces the calcination temperature for the preparation of the solid solution. In addition, the microwaveassisted method offers not only the possibility to obtain high quality powders, but also to obtain well crystallized doped materials such as KNN powders with the advantages of shorter times and in one-step. In other words, further thermal treatment would not be necessary. This is attributed to the effect microwave heating has on the dissolution of the precursors and on the kinetic of crystallization of the final product during the different stages of the hydrothermal process.

\section{Conclusions}

The hydrothermal crystallization method for the synthesis of ceramics was reviewed. Conventional hydrothermal crystallization, surfactant-assisted and microwave-assisted hydrothermal methods were showed as promising methods for the preparation of ceramic powders with novel properties. The synthesis of $\mathrm{BaTiO}_{3}, \mathrm{Li}_{2} \mathrm{SiO}_{3}$ and $\left((\mathrm{Na}, \mathrm{K}) \mathrm{NbO}_{3}\right)$ powders were discussed as cases of study.

$\mathrm{BaTiO}_{3}$ was successfully synthesized at low temperature. The effect of both temperature and reaction time on the crystallization and particle size were studied. The obtained powders show fine particle size in the nanometric range that can offer advantages for the fabrication of homogeneous and fine grain size microstructures through the sintering process.

Crystalline $\mathrm{Li}_{2} \mathrm{SiO}_{3}$ powders were synthesized using TRITON X-114 surfactant. Experimental conditions for obtaining the desirable pure phase of
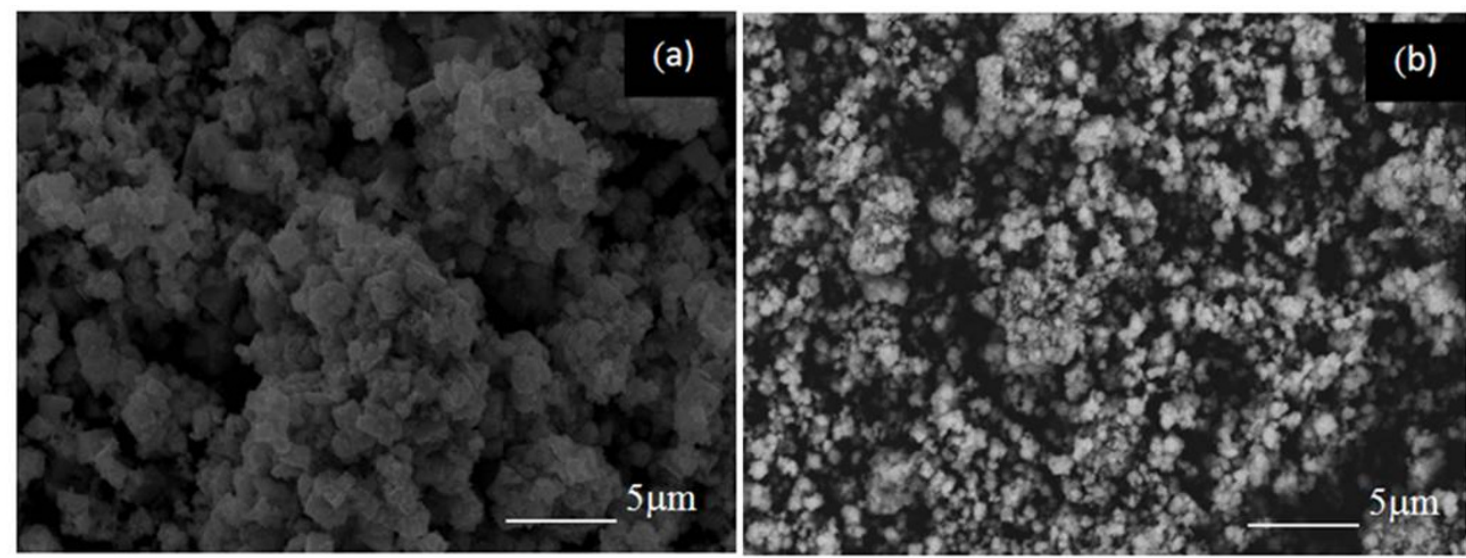

Fig. 10 SEM images of different samples: (a) $\mathrm{CH}$ after calcinations at $800{ }^{\circ} \mathrm{C}$ and (b) MAH powders. 
$\mathrm{Li}_{2} \mathrm{SiO}_{3}$ were established base on the Eh-pH diagrams that constitute a simple resort to estimate phase equilibrium during the hydrothermal processes. The obtained powders show novel microstructures of hollow microspheres exposing high surfaces areas about $69.5 \mathrm{~m}^{2} \mathrm{~g}^{-1}$.

Finally $\mathrm{K}_{0.5} \mathrm{Na}_{0.5} \mathrm{NbO}_{3}$ solid solutions were synthesized by both the conventional and microwaveassisted hydrothermal methods. Conventional method produces ultrafine powders and reduces the temperature for the preparation of the solid solutions by further calcinations. Additionally, the used of microwaves-based heating offers the possibility to obtain well crystallized solid solutions with the advantages of short reaction times and in one-step, which avoids further thermal treatments.

\section{Acknowledgment}

The authors thank to SIP-IPN and SNI-CONACYT México for the financial support. Furthermore, the authors thank to Dr. J.J. Cruz Rivera and M.Sc. Tyler T. Norton for their technical help with TEM analyses and technical support on results discussion, respectively.

\section{References}

[1] Byrappa K, Yoshimura M. Handbook of Hydrothermal Technology. New York: William Andrew, 2001.

[2] Byrappa K, Adschiri T. Progress in Crystal Growth and Characterization of Materials. Amsterdam: Elsevier, 2007.

[3] Lalena JN, Cleary DA, Carpenter E, et al. Inorganic Material Synthesis and Fabrication. New Jersey: John Wiley \& Sons Inc, 2008.

[4] Riman RE, Suchanek WL, Lencka MM. Hydrothermal crystallization of ceramics. Ann Chim Sci Mat 2002, 27: 15-36.

[5] Bucher K, Frey M. Petrogenesis of Metamorphic Rocks. Berlin: Springer, 2002.

[6] Roy R, Tuttle OF. Investigations under hydrothermal conditions. Phys Chem Earth 1956, 1: $138-180$.

[7] Suchanek WL, Riman RE. Hydrothermal synthesis of advanced ceramic powders. Advances in Science and Technology 2006, 45: 184-193.

[8] Tang XL, Xiao XF, Liu RF. Structural characterization of silicon-substituted hydroxyapatite synthesized by a hydrothermal method. Mater Lett 2005, 59: 3841-3846.
[9] Yoshimura M, Sujaridworakun P, Koh F, et al. Hydrothermal conversion of calcite crystals to hydroxyapatite. Mater Sci Eng C 2004, 24: 521-525.

[10] Zhang H, Zhu Q. Structure control in hydroxyapatite synthesis by hydrothermal reaction and organic modulators. Particuology 2005, 3: 317-320.

[11] $\mathrm{Hu} \mathrm{X}$, Shen $\mathrm{H}$, Cheng $\mathrm{Y}$, et al. One-step modification of nano-hydroxyapatite coating on titanium surface by hydrothermal method. Surf Coat Tech 2010, 205: 2000-2006.

[12] Wang H, Lin YS. Effects of synthesis conditions on MFI zeolite membrane quality and catalytic cracking deposition modification results. Micropor Mesopor Mat 2011, 142: 481-488.

[13] Cundy CS, Cox PA. The hydrothermal synthesis of zeolites: Precursors, intermediates and reaction mechanism. Micropor Mesopor Mat 2005, 82: $1-78$.

[14] Whittingham MS, Guo JD, Chen R, et al. The hydrothermal synthesis of new oxide materials. Solid State Ionics 1995, 75: 257-268.

[15] Panda SK, Chaudhuri S. Chelating ligandmediated synthesis of hollow $\mathrm{ZnS}$ microspheres and its optical properties. J Colloid Interf Sci 2007, 313: 338-344.

[16] López-Luke T, De la Rosa E, Sólis D, et al. Effect of the CTAB concentration on the upconversion emission of $\mathrm{ZrO}_{2}: \mathrm{Er}^{3+}$ nanocrystals. Opt Mater 2006, 29: 31-37.

[17] Yang JY, Su YC, Liu XY. Hydrothermal synthesis, characterization and optical properties of $\mathrm{La}_{2} \mathrm{Sn}_{2} \mathrm{O}_{7}: \mathrm{Eu}^{3+}$ micro-octahedra. Nonferrous Met Soc China 2011, 21: 535-543.

[18] Kim JR, Lee KY, Suh MJ, et al. Ceria-zirconia mixed oxide prepared by continuous hydrothermal synthesis in supercritical water as catalyst support. Catal Today 2011, 185: 25-34.

[19] Ifrah S, Kaddouri A, Gelin P, et al. Conventional hydrothermal process versus microwave-assisted hydrothermal synthesis of $\mathrm{La}_{1-x} \mathrm{Ag}_{x} \mathrm{MnO}_{3+\delta}(x=0$, $0.2)$ perovskites used in methane combustion. $C R$ Chimie 2007, 10: 1216-1226.

[20] Solís D, López-Luke T, De la Rosa E, et al. Surfactant effect on the up conversion emission and decay time of $\mathrm{ZrO}_{2}$ : Yb-Er nanocrystals. $J$ Lumin 2009, 129: 449-455.

[21] Zhang DR, Liu HL, Jin RH, et al. Synthesis and characterization of nanocrystalline $\mathrm{LiTiO}_{2}$ using a one-step hydrothermal method. $J$ Ind Eng Chem 2007, 13: 92-96. 
[22] Wang SM, Wang QS, Wan QL. Template-directed synthesis of MS $(\mathrm{M}=\mathrm{Cd}, \mathrm{Zn})$ hollow microsphere via hydrothermal method. J Cryst Growth 2008, 310: 2439-2443.

[23] Piticescu R, Monty C, Millers D. Hydrothermal synthesis of nanostructured zirconia materials: Present state and future prospects. Sensor Actuat B 2005, 109: 102-106.

[24] Kaya C, He JY, Gu X, et al. Nanostructured ceramic powders by hydrothermal synthesis and their applications. Micropor Mesopor Mat 2002, 54: 37-49.

[25] Yan C, Zou L, Xue D, et al. Chemical tuning polymorphology of functional materials by hydrothermal and solvothermal reactions. J Mater Sci 2008, 43: 2263-2269.

[26] Schäf O, Ghobarkar H, Knauth P. Nanostructured Materials: Selected Synthesis Methods, Properties and Applications. Norwell: Kluwer Academic, 2002.

[27] Zeng HC. Ostwald ripening: A synthetic approach for hollow nanomaterials. Current Nanoscience 2007, 3: 177-181.

[28] Meskin PE, Ivanov VK, Barantchikov AE, et al. Ultrasonically assisted hydrothermal synthesis of nanocrystalline $\quad \mathrm{ZrO}_{2}, \quad \mathrm{TiO}_{2}, \quad \mathrm{NiFe}_{2} \mathrm{O}_{4}$ and $\mathrm{Ni}_{0.5} \mathrm{Zn}_{0.5} \mathrm{Fe}_{2} \mathrm{O}_{4}$ powders. Ultrasonics Sonochem 2006, 13: 47-53.

[29] Meskin PE, Sharikov FY, Ivanov VK, et al. Rapid formation of nanocrystalline $\mathrm{HfO}_{2}$ powders from amorphous hafnium hydroxide under ultrasonically assisted hydrothermal treatment. Mater Chem Phys 2007, 104: 439-443.

[30] Rujiwatra A, Wongtaewan C, Pinyo W, et al. Sonocatalyzed hydrothermal preparation of lead titanate nanopowders. Mater Lett 2007, 61: 4522-4524.

[31] Gedanken A. Using sonochemistry for the fabrication of nanomaterials. Ultrason Sonochem 2004, 11: 47-55.

[32] Mason JT. Use of ultrasound in chemical synthesis. Ultrasonics 1986, 24: 245-253.

[33] Manafi S, Nadali H, Irani HR. Low temperature synthesis of multi-walled carbon nanotubes via a sonochemical/hydrothermal method. Mater Lett 2008, 62: 4175-4176.

[34] Li H, Liu G, Chen S, et al. Novel Fe doped mesoporous $\mathrm{TiO}_{2}$ microspheres: Ultrasonichydrothermal synthesis, characterization, and photocatalytic properties. Physica E 2010, 42: 1844-1849.

[35] Suchanek W, Watanabe T, Yoshimura M.
Preparation of $\mathrm{BaTiO}_{3}$ thin films by the hydrothermal-electrochemical method in the flowing solution. Solid State Ionics 1998, 109: 65-72.

[36] Wu Z, Yoshimura M. Investigations on procedures of the fabrication of barium titanate ceramic films under hydrothermal-electrochemical conditions. Solid State Ionics 1999, 122: 161-172.

[37] Hill LI, Verbaere A, Guyomard D. $\mathrm{MnO}_{2}(\alpha-, \beta-, \gamma-)$ compounds prepared by hydrothermalelectrochemical synthesis: characterization, morphology, and lithium insertion behavior. $J$ Power Sources 2003, 119: 226-231.

[38] Yoshimura M, Han KS, Tsurimoto S. Direct fabrication of thin-film $\mathrm{LiNiO}_{2}$ electrodes in $\mathrm{LiOH}$ solution by electrochemical-hydrothermal method. Solid State Ionics 1998, 106: 39-44.

[39] Yoshimura M, Asai O, Cho WS, et al. Low-temperature synthesis of crystallized $\mathrm{Ca}_{1-x} \mathrm{Sr}_{x} \mathrm{TiO}_{3}$ solid-solution films on titanium substrates by a modified hydrothermalelectrochemical technique. J Alloy Compd 1998, 265: 132-136.

[40] Watanabe T, Cho WS, Suchanek WL, et al. Direct fabrication of crystalline vanadates films by hydrothermal-electrochemical method. Solid State Sciences 2001, 3: 183-188.

[41] Xiao XF, Liu RF, Zheng YZ. Hydoxyapatite/ titanium composite coating prepared by hydrothermal-electrochemical technique. Mater Lett 2005, 59: 1660-1664.

[42] Xiao XF, Liu RF, Zheng YZ. Characterization of hydroxyapatite/titania composite coatings codeposited by a hydrothermal-electrochemical method on titanium. Surf Coat Tech 2006, 200: 4406-4413.

[43] Agarwal S, Sharma GL. Humidity sensing properties of $(\mathrm{Ba}, \mathrm{Sr}) \mathrm{TiO}_{3}$ thin films grown by hydrothermal-electrochemical method. Sensor Actuat B 2002, 85: 205-211.

[44] Komarneni S, Roy R, Li QH. Microwavehydrothermal synthesis of ceramic powders. Mat Res Bull 1992, 27: 1393-1405.

[45] Komarneni S, Li Q, Stefansson KM, et al. Microwave-hydrothermal processing for synthesis of electroceramic powders. J Mater Res 1993, 8: 3176-3183.

[46] Bilecka I, Niederberger M. Microwave chemistry for inorganic nanomaterials synthesis. Nanoscale 2010, 2: 1358-1374.

[47] Sun W, Li C, Li J, et al. Microwave-hydrothermal synthesis of tetragonal $\mathrm{BaTiO}_{3}$ under various 
conditions. Mater Chem Phys 2006, 97: 481-487.

[48] Sun W, Li J. Microwave-hydrothermal synthesis of tetragonal barium titanate. Mater Lett 2006, 60: 1599-1602.

[49] Tan CK, Goh GK, Lau GK. Growth and dielectric properties of $\mathrm{BaTiO}_{3}$ thin films prepared by the microwave-hydrothermal method. Thin Solid Films 2008, 516: 5545-5550.

[50] Hu Y, Liu C, Zhang Y, et al. Microwave-assisted hydrothermal synthesis of nanozeolites with controllable size. Micropor Mesopor Mat 2009, 119: 306-314.

[51] Riccardi CS, Lima RC, Dos Santos ML, et al. Preparation of $\mathrm{CeO}_{2}$ by a simple microwavehydrothermal method. Solid State Ionics 2009, 180: 288-291.

[52] Chen Z, Li W, Zeng W, et al. Microwave hydrothermal synthesis of nanocrystalline rutile. Mater Lett 2008, 62: 4343-4344.

[53] Zhang P, Liu B, Yin S, et al. Rapid synthesis of nitrogen doped titania with mixed crystal lattice via microwave-assisted hydrothermal method. Mater Chem Phys 2009, 116: 269-272.

[54] Lee JH, Kim CK, Katoh S, et al. Microwavehydrothermal versus conventional hydrothermal preparation of Ni- and Zn-ferrite powders. J Alloy Compd 2001, 325: 276-280.

[55] Khollam YB, Deshpande SB, Khanna PK, et al. Microwave-accelerated hydrothermal synthesis of blue white phosphor: $\mathrm{Sr}_{2} \mathrm{CeO}_{4}$. Mater Lett 2004, 58: 2521-2524.

[56] Zhang W, Lin D, Sun M, et al. Microwave hydrothermal synthesis and photocatalytic activity of $\operatorname{AgIn}_{5} \mathrm{~S}_{8}$ for the degradation of dye. J Solid State Chem 2010, 183: 2466-2474.

[57] Simoes AZ, Moura F, Onofre TB, et al. Microwave-hydrothermal synthesis of barium strontium titanate nanoparticles. $J$ Alloy Compd 2010, 508: 620-624.

[58] Chen X, Wang W, Chen X, et al. Microwave hydrothermal synthesis and upconversion properties of $\mathrm{NaYF}_{4}: \mathrm{Yb}^{3+}, \mathrm{Tm}^{3+}$ with microtube morphology. Mater Lett 2009, 63: 1023-1026.

[59] Potdar HS, Deshpande SB, Deshpande AS, et al. Preparation of ceria-zirconia $\left(\mathrm{Ce}_{0.75} \mathrm{Zr}_{0.25} \mathrm{O}_{2}\right)$ powders by microwave-hydrothermal $(\mathrm{MH})$ route. Mater Chem Phys 2002, 74: 306-312.

[60] Ji H, Yang G, Miao X, et al. Efficient microwave hydrothermal synthesis of nanocrystalline orthorhombic $\mathrm{LiMnO}_{2}$ cathodes for lithium batteries. Electrochim Acta 2010, 55: 3392-3397.

[61] Vicente I, Cesteros PS, Guirado F, et al. Fast microwave synthesis of hectorite. Appl Clay Sci 2009, 43: 103-107.

[62] Al-Tuwirqi RM, Al-Ghamdi AA, Al-Hazmi F, et al. Synthesis and physical properties of mixed $\mathrm{Co}_{3} \mathrm{O}_{4} / \mathrm{CoO}$ nanorods by microwave hydrothermal technique. Superlattice Microst 2011, 50: 437-448.

[63] Yamauchi T, Tsukahara Y, Sakata T, et al. Barium ferrite powders prepared by microwave-induced hydrothermal reaction and magnetic property. $J$ Magn Magn Mater 2009, 321: 8-11.

[64] Cao SW, Zhu YJ, Cheng GF, et al. $\mathrm{ZnFe}_{2} \mathrm{O}_{4}$ nanoparticles: Microwave-hydrothermal ionic liquid synthesis and photocatalytic property over phenol. J Hazard Mater 2009, 171: 431-435.

[65] Cao SW, Zhu YJ, Cui JB. Iron hydroxyl phosphate microspheres: Microwave-solvothermal ionic liquid synthesis, morphology control, and photoluminescent properties. J Solid State Chem 2010, 183: 1704-1709.

[66] Cao SW, Zhu YJ. Iron oxide hollow spheres: Microwave-hydrothermal ionic liquid preparation, formation mechanism, crystal phase and morphology control and properties. Acta Mater 2009, 57: 2154-2165.

[67] Yin S, Luo Z, Xia J, et al. Microwave-assisted synthesis of $\mathrm{Fe}_{3} \mathrm{O}_{4}$ nanorods and nanowires in an ionic liquid. J Phys Chem Solids 2010, 71: 1785-1788.

[68] Dong WS, Li MY, Liu C, et al. Novel ionic liquid assisted synthesis of $\mathrm{SnO}_{2}$ microspheres. J Colloid Interf Sci 2008, 319: 115-122.

[69] Wang Y, Zhou A, Yang Z. Preparation of hollow $\mathrm{TiO}_{2}$ microspheres by the reverse microemulsions. Mater Lett 2008, 62: 1930-1932.

[70] Tang Z, Hu L, Zhang Z, et al. Hydrothermal synthesis of high surface area mesoporous lithium aluminate. Mater Lett 2007, 61: 570-573.

[71] Liu S, Lebedev OI, Mertens M, et al. The merging of silica-surfactant microspheres under hydrothermal conditions. Micropor Mesopor Mat 2008, 116: 141-146.

[72] Khan F, Eswaramoorthy M, Rao CN. Macroporous silver monoliths using a simple surfactant. Solid State Sci 2007, 9: 27-31.

[73] Turta NA, De Luca P, Bilba N, et al. Synthesis of titanosilicate ETS-10 in presence of cetyltrimethylammonium bromide. Micropor Mesopor Mat 2008, 112: 425-431.

[74] Wang S, Xiu H, Qian L, et al. CTAB-assisted synthesis and photocatalytic property of $\mathrm{CuO}$ hollow microspheres. J Solid State Chem 2009, 182: 1088-1093. 
[75] Zhao Z, Zhang L, Dai H, et al. Surfactant-assisted solvo- or hydrothermal fabrication and characterization of high-surface-area porous calcium carbonate with multiple morphologies. Micropor Mesopor Mat 2011, 138: 191-199.

[76] $\mathrm{Xu} \mathrm{C}$, Zou $\mathrm{D}$, Wang $\mathrm{L}$, et al. $\gamma-\mathrm{Bi}_{2} \mathrm{MoO}_{6}$ nanoplates: Surfactant-assisted hydrothermal synthesis and optical properties. Ceram Int 2009, 35: 2099-2102.

[77] Meng X, Zhang L, Dai H, et al. Surfactant-assisted hydrothermal fabrication and visible-light-driven photocatalytic degradation of methylene blue over multiple morphological $\mathrm{BiVO}_{4}$ single-crystallites. Mater Chem Phys 2011, 125: 59-65.

[78] García-Benjume ML, Espitia-Cabrera MI, Contreras-García ME. Hierarchical macromesoporous structures in the system $\mathrm{TiO}_{2}-\mathrm{Al}_{2} \mathrm{O}_{3}$, obtained by hydrothermal synthesis using Tween- $20^{\circledR}$ as a directing agent. Mater Charact 2009, 60: 1482-1488.

[79] Zhao Q, Wang YG. A facile two-step hydrothermal route for the synthesis of low-dimensional structured $\mathrm{Bi}_{2} \mathrm{Te}_{3}$ nanocrystals with various morphologies. J Alloy Compd 2010, 497: 57-61.

[80] Zhang A, Zhang J. Characterization of visiblelight-driven $\mathrm{BiVO}_{4}$ photocatalysts synthesized via a surfactant-assisted hydrothermal method. Spectrochim Acta A 2009, 73: 336-341.

[81] Qu L, He C, Yang Y, et al. Hydrothermal synthesis of alumina nanotubes templated by anionic surfactant. Mater Lett 2005, 59: 4034-4037.

[82] Wang Y, Zhang S, Wei K, et al. Hydrothermal synthesis of hydroxyapatite nanopowders using cationic surfactant as a template. Mater Lett 2006, 60: $1484-1487$.

[83] Jing Z, Han D, Wu S. Morphological evolution of hematite nanoparticles with and without surfactant by hydrothermal method. Mater Lett 2005, 59: 804-807.

[84] Ji GB, Tang SL, Ren SK, et al. Simplified synthesis of single-crystalline magnetic $\mathrm{CoFe}_{2} \mathrm{O}_{4}$ nanorods by a surfactant-assisted hydrothermal process. J Cryst Growth 2004, 270: 156-161.

[85] Wang J, Hojamberdiev M, Xu Y, et al. Nonionic surfactant-assisted hydrothermal synthesis of $\mathrm{YVO}_{4}: \mathrm{Eu}^{3+}$ powders in a wide $\mathrm{pH}$ range and their luminescent properties. Mater Chem Phys 2011, 125: 82-86.

[86] Sun G, Cao M, Wang Y, et al. Anionic surfactant-assisted hydrothermal synthesis of high-aspect-ratio $\mathrm{ZnO}$ nanowires and their photoluminescence property. Mater Lett 2006, 60:
2777-2782.

[87] Wang YX, Sun J, Fan XY, et al. ACTAB-assisted hydrothermal and solvothermal synthesis of $\mathrm{ZnO}$ nanopowders. Ceram Int 2011, 37: 3431-3436.

[88] Yan H, Zhang XH, Wu JM, et al. The use of CTAB to improve the crystallinity and dispersibility of ultrafine magnesium hydroxide by hydrothermal route. Powder Technol 2008, 188: 128-132.

[89] Flaschen SS. An aqueous synthesis of barium titanate. J Am Chem Soc 1955, 77: 6194-6194.

[90] McCormick MA, Slamovich EB. Microstructure development and dielectric properties of hydrothermal $\mathrm{BaTiO}_{3}$ thin films. J Eur Ceram Soc 2003, 23: 2143-2152.

[91] Lee B, Kim H, Cho S. Hydrothermal preparation of $\mathrm{BaTiO}_{3}$ powders from modified hydroxide precursors. Ferroelectrics 2006, 333: 233-241.

[92] Habib A, Haubner R, Stelzer N. Effect of temperature, time and particle size of Ti precursor on hydrothermal synthesis of barium titanate. Mat Sci Eng B 2008, 152: 60-65.

[93] Hakuta Y, Ura H, Hayashi H, et al. Continuous production of $\mathrm{BaTiO}_{3}$ nanoparticles by hydrothermal synthesis. Ind Eng Chem Res 2005, 44: 840-846.

[94] Zhu X, Zhenghai Z, Zhu J, et al. Morphology and atomic-scale surface structure of barium titanate nanocrystals formed at hydrothermal conditions. $J$ Cryst Growth 2009, 311: 2437-2442.

[95] Oledzka M, Brese NE, Riman RE. Hydrothermal synthesis of $\mathrm{BaTiO}_{3}$ on a titanium-loaded polymer support. Chem Mater 1999, 11: 1931-1935.

[96] Chen C, Wei Y, Jiao X, et al. Hydrothermal synthesis of $\mathrm{BaTiO}_{3}$ : Crystal phase and the $\mathrm{Ba}^{2+}$ ions leaching behavior in aqueous medium. Mater Chem Phys 2008, 110: 186-191.

[97] Cruz D, Bulbulian S, Lima E, et al. Kinetic analysis of the thermal stability of lithium silicates $\left(\mathrm{Li}_{4} \mathrm{SiO}_{4}\right.$ and $\left.\mathrm{Li}_{2} \mathrm{SiO}_{3}\right)$. J Solid State Chem 2006, 179: 909-916.

[98] Tang T, Zhang Z, Meng JB, et al. Synthesis and characterization of lithium silicate powders. Fusion Eng Des 2009, 84: 2124-2130.

[99] Furusawa SI, Kamiyama A, Tsurui T. Fabrication and ionic conductivity of amorphous lithium meta-silicate thin film. Solid State Ionics 2008, 179: 536-542.

[100] Furusawa SI, Kasahara T, Kamiyama A. Fabrication and ionic conductivity of $\mathrm{Li}_{2} \mathrm{SiO}_{3}$ thin film. Solid State Ionics 2009, 180: 649-653.

[101] Naik YP, Mohapatra M, Dahale ND, et al. 
Synthesis and luminescence investigation of $\mathrm{RE}^{3+}$ $\left(\mathrm{Eu}^{3+}, \mathrm{Tb}^{3+}\right.$ and $\left.\mathrm{Ce}^{3+}\right)$-doped lithium silicate $\left(\mathrm{Li}_{2} \mathrm{SiO}_{3}\right)$. J Lumin 2009, 129: 1225-1229.

[102] Morimoto S, Khonthon S, Ohishi Y. Optical properties of $\mathrm{Cr}^{3+}$ ion in lithium metasilicate $\mathrm{Li}_{2} \mathrm{O} \cdot \mathrm{SiO}_{2}$ transparent glass-ceramics. J Non-Cryst Solids 2008, 354: 3343-3347.

[103] Zhang B, Nieuwouldt M, Easteal AJ. Sol-gel route to nanocrystalline lithium metasilicate particles. $J$ Am Ceram Soc 2008, 91: 1927-1932.

[104] Khomane RB, Sharma BK, Saha S, et al. Reverse microemulsion mediated sol-gel synthesis of lithium silicate nanoparticles under ambient conditions: Scope for $\mathrm{CO}_{2}$ sequestration. Chem Eng Sci 2006, 61: 3415-3418.

[105] Mondragón-Gutiérrez G, Cruz D, Pfeiffer H, et al. Low temperature synthesis of $\mathrm{Li}_{2} \mathrm{SiO}_{3}$ : Effect on its morphological and textural properties. Research Letters in Materials Science 2008, 25: 2513-2522.

[106] Linkson PB, Phillips BD, Rowles CD. Computer methods for the generation of Eh-pH diagrams. Minerals Sci Eng 1979, 11: 65-79.

[107] Dias A. Thermodynamic studies as predictive tools of the behavior of electroceramics under different hydrothermal environments. J Solution Chem 2009, 38: 843-856.

[108] Lencka MM, Riman RE. Synthesis of lead titanate: Thermodynamic modeling and experimental verification. $J \mathrm{Am}$ Ceram Soc 1993, 76: 2649-2659.

[109] Lencka MM, Riman RE. Thermodynamic modeling of hydrothermal synthesis of ceramic powders. Chem Mater 1993, 5: 61-70.

[110] Lencka MM, Riman RE. Thermodynamics of the hydrothermal synthesis of calcium titanate with reference to other alkaline-earth titanates. Chem Mater 1995, 7: 18-25.

[111] Information on www.factsage.com.

[112] Ortiz Landeros J, Contreras García ME, Gómez Yáñez C, et al. Surfactant-assisted hydrothermal crystallization of nanostructured lithium metasilicate $\left(\mathrm{Li}_{2} \mathrm{SiO}_{3}\right)$ hollow spheres: Synthesis, structural and microstructural characterization. $J$ Solid State Chem 2011, 184: 1304-1311.

[113] Sing K. The use of nitrogen adsorption for the characterisation of porous materials. Colloid Surface A 2001, 187: 3-9.

[114] Leofanti G, Padovan M, Tozzola G, et al. Surface area and pore texture of catalysts. Catal Today 1998, 41: 207-219.

[115] Sing KS, Everett DH, Haul RA, et al. Reporting physisorption data for gas/solid systems with special reference to the determination of surface area and porosity. Pure Appl Chem 1985, 57: 603-619.

[116] Ringgaard E, Wurlitzer T. Lead-free piezoceramics based on alkali niobates. J Eur Ceram Soc 2005, 25: 2701-2706.

[117] Hao J, Wang X, Chen R, et al. Synthesis of $\left(\mathrm{Bi}_{0.5} \mathrm{Na}_{0.5}\right) \mathrm{TiO}_{3}$ nanocrystalline powders by stearic acid gel method. Mater Chem Phys 2005, 90: 282-285.

[118] Fu ST, Hong LD, Wan C, et al. Preparation and properties of $\left(\mathrm{K}_{0.5} \mathrm{Na}_{0.5}\right) \mathrm{NbO}_{3}-\mathrm{LiNbO}_{3}$ ceramics. Trans Nonferrous Met Soc China 2006, 16: 466-469.

[119] Wang Y, Yi Z, Li Y, et al. Hydrothermal synthesis of potassium niobate powders. Ceram Int 2007, 33: 1611-1615.

[120] Lu CH, Lo SY, Lin HC. Hydrothermal synthesis of nonlinear optical potassium niobate ceramic powder. Mater Lett 1998, 34: 172-176.

[121] Jing X, Li Y, Yin Q. Hydrothermal synthesis of $\mathrm{Na}_{0.5} \mathrm{Bi}_{0.5} \mathrm{TiO}_{3}$ fine powders. Mater Sci Eng $B$ 2003, 99: 506-510.

[122] Lin D, Xiao D, Zhu J, et al. Synthesis and piezoelectric properties of lead-free piezoelectric $\left[\mathrm{Bi}_{0.5}\left(\mathrm{Na}_{1-x-y} \mathrm{~K}_{x} \mathrm{Li}_{y}\right)_{0.5}\right] \mathrm{TiO}_{3}$ ceramics. Mater Lett 2004, 58: 615-618.

[123] Peng C, Gong W. Preparation and properties of $\left(\mathrm{Bi}_{1 / 2} \mathrm{Na}_{1 / 2}\right) \mathrm{TiO}_{3}-\mathrm{Ba}(\mathrm{Ti}, \mathrm{Zr}) \mathrm{O}_{3} \quad$ lead-free piezoelectric ceramics. Mat Lett 2005, 59: 1576-1580.

[124] Wang X, Chan HL, Choy C. Piezoelectric and dielectric properties of $\mathrm{CeO}_{2}$-added $\left(\mathrm{Bi}_{0.5} \mathrm{Na}_{0.5}\right)_{0.94} \mathrm{Ba}_{0.06} \mathrm{TiO}_{3}$ lead-free ceramics. Solid State Comm 2003, 125: 395-399.

[125] Jaeger RE, Egerton L. Hot pressing of potassium-sodium niobates. J Am Ceram Soc 1962, 45: 209-213.

[126] Wu L, Zhang JL, Wang CL, et al. Influence of compositional ratio $\mathrm{K} / \mathrm{Na}$ on physical properties in $\left(\mathrm{K}_{x} \mathrm{Na}_{1-x}\right) \mathrm{NbO}_{3}$ ceramics. J Appl Phys 2008, 103: 084116.

[127] Shiratori Y, Magrez A, Pithan C. Particle size effect on the crystal structure symmetry of $\mathrm{K}_{0.5} \mathrm{Na}_{0.5} \mathrm{NbO}_{3}$. J Eur Ceram Soc 2005, 25: 2075-2079.

[128] Chowdhury A, Bould J, Zhang Y, et al. Nano-powders of $\mathrm{Na}_{0.5} \mathrm{~K}_{0.5} \mathrm{NbO}_{3}$ made by a sol-gel method. J Nanopart Res 2010, 12: 209-215.

[129] Chowdhury A, O'Callaghan S, Skidmore TA, et al. Nanopowders of $\mathrm{Na}_{0.5} \mathrm{~K}_{0.5} \mathrm{NbO}_{3}$ prepared by the 
Pechini method. J Am Ceram Soc 2009, 92: 758-761.

[130] Sun C, Xing X, Chen J, et al. Hydrothermal synthesis of single krystalline $(\mathrm{K}, \mathrm{Na}) \mathrm{NbO}_{3}$ powders. Eur J Inorg Chem 2007, 18: 1884-1888.

[131] Lv JH, Zhang M, Guo M, et al. Hydrothermal synthesis and characterization of $\mathrm{K}_{x} \mathrm{Na}_{(1-x)} \mathrm{NbO}_{3}$ powders. Int J Appl Ceram Technol 2007, 4: 571-577.

[132] Santos IC, Loureiro LH, Silva MF, et al. Studies on the hydrothermal synthesis of niobium oxides.
Polyhedron 2002, 21: 2009-2015.

[133] Wang X, Zheng S, Zhang Y. A novel method to prepare ultrafine potassium tantalate powders. Mater Lett 2008, 62: 1212-1214.

[134] Liu JF, Li XL, Li YD. Synthesis and characterization of nanocrystalline niobates. $J$ Cryst Growth 2003, 247: 419-424.

[135] Maeda T, Takiguchi N, Ishikawa $\mathrm{M}$, et al. (K, $\mathrm{Na}) \mathrm{NbO}_{3}$ lead-free piezoelectric ceramics synthesized from hydrothermal powders. Mater Lett 2010, 64: 125-128. 